\title{
Hydroxyapatite Coatings on Calcite Powder for the Removal of Heavy Metals from Contaminated Water
}

\author{
Oriol Gibert ${ }^{1,2, *}$, César Valderrama ${ }^{1,2} \mathbb{D}$, María M. Martínez ${ }^{1,2}$, Rosa Mari Darbra ${ }^{1}$, Josep Oliva Moncunill ${ }^{1}$ \\ and Vicenç Martí 1,2,3 (D)
}

1 Chemical Engineering Department, EEBE, Technical University of Catalonia (UPC), Av. Eduard Maristany 16, 08019 Barcelona, Spain; cesar.alberto.valderrama@upc.edu (C.V.); maria.rosario.martinez@upc.edu (M.M.M.); rm.darbra@upc.edu (R.M.D.); josep.oliva@upc.edu (J.O.M.); vicens.marti@upc.edu (V.M.)

2 Barcelona Research Center in Multiscale Science and Engineering, EEBE, Technical University of Catalonia (UPC), Av. Eduard Maristany 16, 08019 Barcelona, Spain

3 Eurecat-Centre Tecnològic de Catalunya, Sustainability Area, Pça. de la Ciència 2, 08243 Manresa, Spain

* Correspondence: oriol.gibert@upc.edu

Citation: Gibert, O.; Valderrama, C.; Martínez, M.M.; Darbra, R.M.;

Moncunill, J.O.; Martí, V.

Hydroxyapatite Coatings on Calcite Powder for the Removal of Heavy Metals from Contaminated Water. Water 2021, 13, 1493. https:// doi.org/10.3390/w13111493

Academic Editor: Laura Bulgariu

Received: 16 April 2021

Accepted: 23 May 2021

Published: 27 May 2021

Publisher's Note: MDPI stays neutral with regard to jurisdictional claims in published maps and institutional affiliations.

Copyright: (C) 2021 by the authors Licensee MDPI, Basel, Switzerland. This article is an open access article distributed under the terms and conditions of the Creative Commons Attribution (CC BY) license (https:/ / creativecommons.org/licenses/by/ $4.0 /)$.

\begin{abstract}
An approach for the remediation of heavy metal-contaminated wastewater that is gaining increasing attention is the application of hydroxyapatite (HAP)-based particles. HAP is conventionally synthesized through wet chemical precipitation of calcium and phosphate ions, although later studies have focused on HAP synthesis from solid calcite contacted with a phosphate solution under ambient conditions. This synthesis route can allow saving soluble Ca-chemicals and, thus, make the process more cost-efficient. The aim of this study was to coat natural calcite powder with a layer of HAP for the removal of $\mathrm{Zn}$ and $\mathrm{Cu}$ from contaminated water. For this purpose, a HAP layer was synthesized on calcite particles, characterized using several complementary techniques and evaluated for the removal of $\mathrm{Zn}$ and $\mathrm{Cu}$ from synthetic solutions. Sorption kinetics and equilibrium isotherms, as well as the effect of sonication of the synthesized sample on its sorption performance, were determined. The results showed that calcite particles were efficiently coated with a HAP layer with high capacity in removing $\mathrm{Zn}$ and $\mathrm{Cu}$ from acidic solutions, with a $\mathrm{q}_{\max }$ of $34.97 \mathrm{mg} / \mathrm{g}$ for $\mathrm{Zn}$ (increased to $37.88 \mathrm{~g} / \mathrm{mg}$ after sonication of the sample) and $60.24 \mathrm{mg} / \mathrm{g}$ for $\mathrm{Cu}$ (which hardly varied with sonication). The mechanisms behind the sorption of $\mathrm{Zn}$ and $\mathrm{Cu}$ onto $\mathrm{HAP}$, inferred from $\mathrm{pH}$ changes, the relation between metal uptake and $\mathrm{Ca}^{2+}$ release and $\mathrm{XRD}$ analysis, included surface complexation, ion exchange and precipitation of new $\mathrm{Zn}$ - and $\mathrm{Cu}$-containing phases.
\end{abstract}

Keywords: hydroxyapatite; calcium carbonate; coating; heavy metal sorption; groundwater remediation

\section{Introduction}

Acidic metal-rich wastewater from mining and industrial processes represents an environmental problem worldwide due to its low $\mathrm{pH}$ and high content of heavy metals. It is well-known that heavy metals discharged into the environment may pose a serious hazard to all living beings because of their bioaccumulation and toxicity even at low concentrations [1,2]. Therefore, removal of heavy metals from this type of wastewater by an appropriate treatment becomes necessary.

When wastewater can be managed on the surface, above-ground engineered systems offer the opportunity to customize the operation conditions for an optimized performance. The removal of heavy metals in these systems can be achieved through several processes, with the most common ones being chemical precipitation, coagulation-flocculation, membrane filtration, ion-exchange, electrochemical processes and sorption. Chemical precipitation is the simplest and most employed approach, although it consumes large amounts of chemicals and can generate an excessive amount of sludge that requires further treatment $[3,4]$. Coagulation-flocculation also removes heavy metals from water with reduced time to settle suspended solids, but like chemical filtration, it produces huge amounts of 
sludge that need to be handled and treated [3,5]. Membrane filtration (particularly nanofiltration and reverse osmosis) is recognized as a very efficient technology for the removal of dissolved heavy metals, although it usually requires high energy consumption and suffers from membrane fouling, posing difficulties in their operation and increasing operation costs [6,7]. Ion-exchange has also proved to be useful for the removal and recovery of heavy metals from water. It offers the advantages of selective removal and no sludge production, but on the other hand, ion-exchange resins are expensive and their regeneration can increase the cost even further. Moreover, successful removal by ion-exchange is applicable to only a limited number of metal cations [5,8]. Electrochemical methods are also an option to remove heavy metals from water, but they are usually associated to high costs and high electrical supply [3,7]. Finally, sorption arises as one of the most attractive methods thanks to its efficiency, versatility, simplicity in design and operation and low cost $[5,9]$. Sorption-based approaches are spreading as new sorbents and applications are researched. Within this context, the recent developments in micro- and nano-particles (MPs and NPs) with sorption capacity towards metals are gaining increased attention of researchers [2,10].

When contaminated water is groundwater (e.g., when mining acidic metal-rich streams known as acid mine drainage (AMD) percolate through the soil), the selection of the most suitable technology becomes more complicated. First, some of the above-mentioned processes (e.g., membrane filtration or ion-exchange) are technically impractical at depth and/or are cost-prohibitive when applied on surface after groundwater extraction. In these cases, in-situ remediation in the aquifer itself through the installation of a permeable reactive barrier (PRB) [11], the insertion into the subsoil of electrodes to promote electrochemical processes [12] or the introduction of reactive chemicals via injection wells [13] has become a matter of active research. Despite successful experiences, PRBs have shown to be restricted to shallow aquifers and often suffer from limited capture of the contaminated plume [11,14]. For their part, technologies based on in-situ-induced electrochemical processes are constrained by the limited metal removal and high energy consumption [12]. Another promising approach for in-situ remediation that is gaining increasing attention of researchers is the application of MPs and NPs in the subsoil able to immobilize, neutralize or decompose the contaminants present in groundwater, as the application of MPs and NPs allows reaching contaminants in deep aquifers not accessible by PRBs [10,15].

Many different materials have been evaluated for their application in the form of MPs and NPs $[16,17]$. For the removal of heavy metals, powders based on hydroxyapatite $\left(\mathrm{Ca}_{10}\left(\mathrm{PO}_{4}\right)_{6}(\mathrm{OH})_{2}\right.$, hereafter referred to as HAP) have been acknowledged as one of the most suitable reactants thanks to its high sorption capacity for heavy metals, low water solubility, availability and low cost, environmental compatibility and high stability under oxidizing and reducing conditions [18-20].

Properties (and thus performance) of a given HAP greatly depend on how it has been synthesized [21,22]. Among the conventional methods of producing HAP particles, the classical wet chemical precipitation (i.e., soluble $\mathrm{Ca}^{2+}$ and $\mathrm{HPO}_{4}{ }^{2-}$ are precipitated in an aqueous solution at basic conditions) is often reported to be the most convenient one because, unlike more sophisticated strategies, it is not associated to high cost and energy use $[23,24]$. The final composition, morphology and properties of the synthesized HAP following the wet precipitation method depend on many variables, such as concentration and proportion of precursors, $\mathrm{pH}$, temperature, presence of other ionic species or organic compounds and aging time $[21,25,26]$. Numerous studies have demonstrated that HAPs with high sorption capacity for metals can be synthesized over a wide range of values for these variables.

Modifications of the classical wet chemical precipitation of HAP have been investigated in other fields. HAP has been synthesized, under ambient conditions, from solid calcite contacted with a phosphate solution, on the basis that the solid calcite acts as a source of $\mathrm{Ca}^{2+}$ instead of externally adding it in the form of soluble $\mathrm{Ca}^{2+}$. Under this 
scheme, $\mathrm{Ca}^{2+}$ is supplied by dissolution of $\mathrm{CaCO}_{3}$ and precipitated by the following overall reaction:

$$
10 \mathrm{CaCO}_{3}(\mathrm{~s})+6 \mathrm{HPO}_{4}{ }^{2-}+4 \mathrm{H}_{2} \mathrm{O} \rightarrow \mathrm{Ca}_{10}\left(\mathrm{PO}_{4}\right)_{6}(\mathrm{OH})_{2}+10 \mathrm{HCO}_{3}{ }^{-}+2 \mathrm{OH}^{-}
$$

This approach has been applied for the synthesis of HAP from biogenic calcite (e.g., nacre, oyster shells, sea urchin spines or other natural osteo-inductive biomaterials) [20,26-28]. Further studies have compared the effect of using different orthophosphate sources in such a synthesis route [29]. In addition, under this scheme, studies aiming at protecting marble sculptures and monuments from acid rain have investigated the possibility of coating them with a film of HAP synthesized by using the marble itself as a $\mathrm{Ca}^{2+}$ source for the HAP [30-32]. Although these studies provide very promising results, further investigation is needed to fully understand $\mathrm{HAP}$ synthesis from solid $\mathrm{CaCO}_{3}$.

From a remediation perspective, preparing calcite particles coated by HAP for sorbing metals would allow saving huge amounts of soluble Ca-chemicals and, thus, make the process more cost-efficient and improve its competitiveness. Solid calcite, as one of the fifth most abundant biominerals in the Earth crust, has a very low cost and wide availability. However, to the best of our knowledge, there is a lack of studies from such a standpoint and only an attempt has been made to synthesize phosphatized dolomite as sorbent to be used for the treatment of metal-contaminated water [33].

Within this context, the aim of this bench-scale study was to coat natural calcite powders with a layer of HAP for the removal of heavy metal ions $(\mathrm{Cu}$ and $\mathrm{Zn})$ from contaminated water. $\mathrm{Zn}$ and $\mathrm{Cu}$ ions were chosen as representative heavy metals, with wide presence in the environment caused mainly by human activity. The specific objectives were (1) to synthesize and characterize a layer of HAP on solid calcite particles, (2) to assess its sorption capacity toward $\mathrm{Zn}$ and $\mathrm{Cu}$ in single-metal solutions, determining the sorption kinetics and the equilibrium isotherms (and to compare them with those of commercial HAPs), (3) to evaluate the effect of sonicating the material on sorption performance and (4) to infer the mechanisms responsible for the removal of $\mathrm{Zn}$ and $\mathrm{Cu}$.

\section{Materials and Methods}

\subsection{Bare Calcite MPs and Chemical Reagents}

The commercial calcite MPs were purchased from Reverté S.A. (Spain). The MPs were found to have an average particle size of $10 \mu \mathrm{m}$ and exhibit a BET surface area of $0.87 \mathrm{~m}^{2} / \mathrm{g}$. The acid digestion of calcite MPs and analysis by ICP-OES showed a composition of $36.5 \%$ $\mathrm{Ca}$ and $0.17 \% \mathrm{Mg}$. Precursors $\left(\mathrm{NH}_{4}\right)_{2} \mathrm{HPO}_{4}$ (Scharlau $\left.\geq 98 \%\right), \mathrm{CaCl}_{2}($ Panreac $\geq 98 \%$ ), $\mathrm{NaOH}$ (Panreac $\geq 98 \%$ ) and ethanol (Scharlau $\geq 96 \%$ ) were used for HAP synthesis. For sorption experiments, acidic $\mathrm{Zn}$ and $\mathrm{Cu}$ solutions were prepared from their $\mathrm{ZnCl}_{2}$ and $\mathrm{CuSO}_{4}$ salts (Panreac $\geq 98 \%$ ) and $\mathrm{HNO}_{3}$ (Panreac $\geq 96 \%$ ). Performance of synthesized HAP was compared against commercial micro-HAP (Acros 35-40\% in Ca) and nano-HAP (Merck $\geq 97 \%$ ), labeled hereafter as mHAPcom and nHAPcom, respectively.

\subsection{Synthesis Route of HAP Coatings on Calcite MPS}

The synthesis route of the HAP coating consisted of a two-step procedure based on that applied by Graziani et al. for the coverage of marble with a HAP film [32]. First, $1 \mathrm{~g}$ of calcite MPs was placed in a plastic centrifuge tube and put into contact with $25 \mathrm{~mL}$ of a solution containing $\left(\mathrm{NH}_{4}\right)_{2} \mathrm{HPO}_{4}(0.1 \mathrm{M}), \mathrm{CaCl}_{2}(0.1 \mathrm{M})$ and a $\mathrm{pH}$ of 8 in the presence of ethanol $0.5 \%$, as ethanol has been found to improve the coverage of a calcite surface by a more uniform, crack-free and thinner layer of HAP [32]. The $\mathrm{pH}$ was adjusted by adding $\mathrm{NaOH}$ dropwise until the desired value was achieved. Second, a further precipitation of HAP following the same procedure and concentrations as described above but without ethanol was carried out.

For each step, the suspension was shaken in a rotary shaker (Heidolph $\mathrm{GmbH}$, REAX 20, Schwabach, Germany) for $24 \mathrm{~h}$. This time was chosen to allow possible precipitated intermediates (octacalcium phosphate, amorphous calcium phosphate, calcium- 
deficient hydroxyapatite) to shift to HAP [23]. After $24 \mathrm{~h}$, the synthesized solid (HAP-coated calcite MPs) was separated by centrifugation (J.P. Selecta, Centronic-BLT, Abrera, Spain) at $4000 \mathrm{rpm}$ for $20 \mathrm{~min}$, oven-dried (J.P. Selecta, Digiheat, Abrera, Spain) at $110{ }^{\circ} \mathrm{C}$ for $1.5 \mathrm{~h}$ and ground with a mortar before further use. This material was labelled "synt" (from synthesized).

In order to diminish the particle size of the selected material and thus potentially enhance its sorption capacity, a portion of it was subjected to sonication, as it is known that ultrasonic energy applied to a suspension can lead to breakage of agglomerated particles. Sonication of a sample of $4 \mathrm{~g}$ in $250 \mathrm{~mL}$ of deionized water was conducted in an ultrasonic cleaner (ATU Ultrasonidos, ATM40-2L-CD, Paterna, Spain) operating at a fixed frequency of $40 \mathrm{~Hz}$ for $30 \mathrm{~min}$. The solid was then separated by centrifugation and dried as described above. The modified material was labelled "son" (from sonicated).

Performance of samples "synt" and "son" were compared against that of commercial HAP samples mHAPcom (micro-size) and nHAPcom (nano-size).

\subsection{Characterization of the HAP-Coated MPs Samples}

The synthesized material and its sonicated sub-sample were characterized using several complementary techniques. Functional groups were characterized employing a Fourier Transform Infrared (FTIR) spectrophotometer (Nicolet 6700, Madison, WI, USA) fitted with an Attenuated Total Reflectance (ATR) accessory (Smart Orbit). Mineralogical identity and crystallinity were analyzed by X-ray powder diffraction (XRD) recorded on a Bruker D8 Advance diffractometer. Morphology was viewed with a Focused Ion BeamScanning Electron Microscope (FIB-SEM) equipped with an energy dispersive spectrometer (EDS) for elemental analysis (Carl Zeiss Neon40, Jena, Germany). Samples were mounted on stainless-steel stubs using a double-sided adhesive carbon disc and sputter-coated with a thin layer of carbon to render them conductive for SEM observation. The specific BET surface area $\left(\mathrm{S}_{\mathrm{BET}}\right)$ of the samples was measured by $\mathrm{N}_{2}$ adsorption according to the Brunauer-Emmet-Teller method in a SBET analyzer (Micromeritics ASAP 2020, Aachen, Germany). Degassing and heating was carried out at a maximum temperature of $250{ }^{\circ} \mathrm{C}$. Particle size distribution (PSD) was determined using a Laser Diffraction Particle Size analyzer (Malvern Panalyitical, MasterSizer 3000, Worcestershire, UK) with a Hydro EV wet dispersion unit. For calculations, the Mie theory was chosen, and refractive and absorption indices were 1.630 and 0.010 , respectively. In order to obtain PSD of particles in the same conditions of the experiments, measurements were carried out with water and without application of ultrasounds. PSD curves provided by the instrument were given as volumetric PSD. The $\mathrm{pH}$ at the point zero charge $\left(\mathrm{pH}_{\mathrm{PZC}}\right)$ was estimated through the immersion technique by putting an amount of solid material in contact with solutions at different initial $\mathrm{pHs}$ and measuring the change of $\mathrm{pH}(\Delta \mathrm{pH})$ once equilibrium was reached [34].

\subsection{Sorption Performance of the Synthesized HAP-Coated Material}

\subsubsection{General Procedure}

All sorption experiments were carried out using standard batch methodology. Known volumes $(50 \mathrm{~mL})$ of prepared solutions of $\mathrm{Zn}$ and $\mathrm{Cu}$ (added in the form of $\mathrm{ZnCl}_{2}$ and $\left.\mathrm{CuSO}_{4}\right)$ at $\mathrm{pH} 4.6$ were contacted with a weighted amount of sorbent in plastic centrifuge tubes and shaken in a rotatory shaker for $24 \mathrm{~h}$ at room temperature $\left(21 \pm 2{ }^{\circ} \mathrm{C}\right)$. For the kinetics study, the weighted amount was $0.05 \mathrm{mg}$, the $\mathrm{Zn}$ or $\mathrm{Cu}$ concentration was $50 \mathrm{mg} / \mathrm{L}$ and the supernatant solution samples were collected at predetermined time intervals (after $1,2,4,6,9,12,15,25,40,60 \mathrm{~min})$. For the equilibrium experiments, the weighted amounts of sorbent were 0.05 or $0.1 \mathrm{~g}$, and the initial $\mathrm{Zn}$ or $\mathrm{Cu}$ concentrations were 5, 10, 20, 40, $60,80,100$ and $120 \mathrm{mg} / \mathrm{L}$. The ratio of aqueous phase volume $(\mathrm{mL})$ to sorbent weight (mg) was varied as necessary to observe a measurable decrease in the concentration of $\mathrm{Zn}$ and $\mathrm{Cu}$ in the aqueous solution once the equilibrium was reached. No pH control was imposed during sorption experiments in order to mimic the subsoil conditions during the 
remediation of contaminated groundwater. All centrifuge tubes were shaken in a rotary shaker at $50 \mathrm{rpm}$ for $24 \mathrm{~h}$, after which the supernatant solution was separated from the sorbent by centrifugation at $4000 \mathrm{rpm}$ for $10 \mathrm{~min}$, filtered $(0.22 \mu \mathrm{m})$, acidified $\left(1 \% \mathrm{HNO}_{3}\right)$ and transferred to auto-sampler vials for analysis of the remaining $\mathrm{Zn}$ and $\mathrm{Cu}$. The ions $\mathrm{Ca}^{2+}, \mathrm{HPO}_{4}{ }^{2-}$ and $\mathrm{pH}$ in the supernatant were also determined in separate aliquots.

\subsubsection{Sorption Kinetics of $\mathrm{Zn}$ and $\mathrm{Cu}$}

The kinetics of the sorption of $\mathrm{Zn}$ and $\mathrm{Cu}$ onto the HAP was fitted using the pseudo first-order and the pseudo second-order kinetics models, whose linearized forms are, respectively:

$$
\begin{gathered}
\log \left(\mathrm{q}_{\mathrm{e}}-\mathrm{q}\right)=\log \mathrm{q}_{\mathrm{e}}-\frac{\mathrm{k}_{1}}{\mathrm{e}} \times \mathrm{t} \\
\frac{\mathrm{t}}{\mathrm{q}}=\frac{1}{\mathrm{k}_{2} \times \mathrm{q}_{\mathrm{e}}^{2}}+\frac{\mathrm{t}}{\mathrm{q}_{\mathrm{e}}}
\end{gathered}
$$

where $\mathrm{q}$ and $\mathrm{q}_{\mathrm{e}}$ are the amounts of adsorbed metal per weight unit of adsorbent $(\mathrm{mg} / \mathrm{g}$ ) at equilibrium and at time $t$ respectively, and $k_{1}$ and $k_{2}$ are the rate constants of pseudo first-order $\left(\mathrm{min}^{-1}\right)$ and pseudo second-order $\left(\mathrm{g} \cdot \mathrm{mg}^{-1} \cdot \mathrm{min}^{-1}\right)$, respectively.

The amount of adsorbed metal per weight unit of the adsorbent (q, in $\mathrm{mg} / \mathrm{g}$ ) was calculated from the following mass balance, also valid for the equilibrium:

$$
\mathrm{q}_{\mathrm{e}}=\frac{\mathrm{V} \times\left(\mathrm{c}_{\mathrm{i}}-\mathrm{c}_{\mathrm{e}}\right)}{\mathrm{w}}
$$

where $c_{i}$ and $c_{e}$ are the initial and equilibrium concentrations of the metal ion in the bulk solution $(\mathrm{mg} / \mathrm{L}), \mathrm{V}$ is the volume of the solution $(\mathrm{L})$ and $\mathrm{w}$ is the weight of the sorbent $(\mathrm{g})$.

\subsubsection{Sorption Isotherms for Single-Metal Systems}

Sorption equilibrium data are usually plotted as an isotherm displaying the content of the sorbed species on the sorbent $\left(\mathrm{q}_{\mathrm{e}}\right)$ (in $\mathrm{mg} / \mathrm{g}$ ) versus the concentration of the remaining aqueous species $\left(\mathrm{c}_{\mathrm{e}}\right)$ (in $\mathrm{mg} / \mathrm{L}$ ). The sorption data of this study were modeled taking into account the concentration of ions in both phases and according to the widely used Langmuir equations:

$$
\mathrm{q}_{\mathrm{e}}=\frac{\mathrm{K}_{\mathrm{L}} \times \mathrm{q}_{\max } \times \mathrm{c}_{\mathrm{e}}}{1+\mathrm{K}_{\mathrm{L}} \times \mathrm{c}_{\mathrm{e}}}
$$

where $\mathrm{q}_{\max }$ is the maximum adsorption capacity $(\mathrm{mg} / \mathrm{g})$ and $\mathrm{K}_{\mathrm{L}}$ is the Langmuir binding constant, which is related to the energy of adsorption $(\mathrm{L} / \mathrm{mg})$. Experimental $\mathrm{c}_{\mathrm{e}}$ and $\mathrm{q}_{\mathrm{e}}$ data were used to determine the constants $\left(\mathrm{q}_{\max }, \mathrm{K}_{\mathrm{L}}\right)$ for each metal and sorbent from the linearized form of the Langmuir isotherm and using least-square regression analysis.

\subsection{Water Analysis}

Measurements of $\mathrm{pH}$ were made with a Hamilton combination $\mathrm{pH}$ electrode coupled to a Crison GLP22 $\mathrm{pH}$ meter. $\mathrm{HPO}_{4}{ }^{2-}$ and $\mathrm{Ca}^{2+}$ in the supranatants in the sorption experiments were analyzed by ionic chromatography (IC) (Dionex, ICS-1000, Sunny Valley, ID, USA) equipped with cationic and anionic detectors (ICS-1000 and ICS-1100, respectively) and controlled by software Chromeleon ${ }^{\circledR}$ chromatographic. $\mathrm{Ca}, \mathrm{P}$ and $\mathrm{Mg}$ (in the determination of the calcite composition), and $\mathrm{Zn}$ and $\mathrm{Cu}$ (in the sorption experiments) were analyzed by atomic absorption spectroscopy (AAS) (Varian, SpectraAA 50-B, Palo Alto, CA, USA) and inductively coupled plasma optical emission spectrometry (ICP-OES) (Perkin Elmer, Optima 8300, Waltham, MA, USA).

\section{Results and Discussion}

\subsection{Characterization of the Synthesized Material}

Figure 1 displays the FTIR spectra (a) and the XRD spectra (b) of the "synt" sample and, for comparison, calcite and a commercial HAP (mHAPcom). 
(a) FTIR analysis

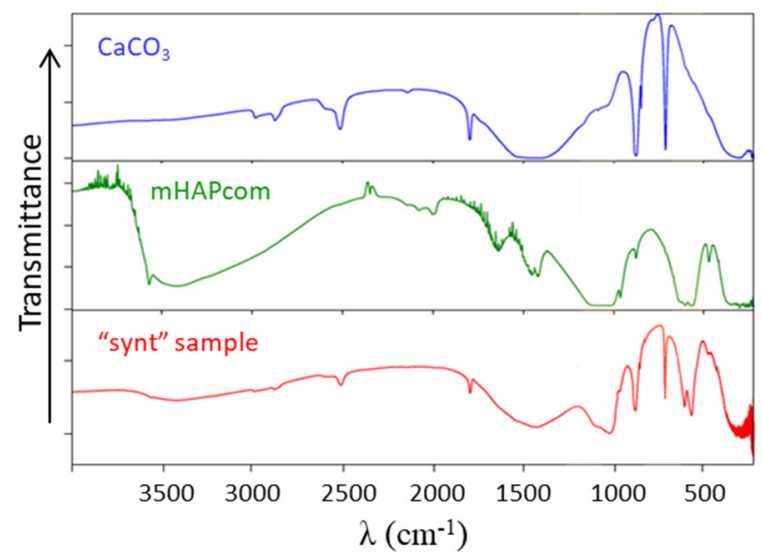

(b) XRD analysis

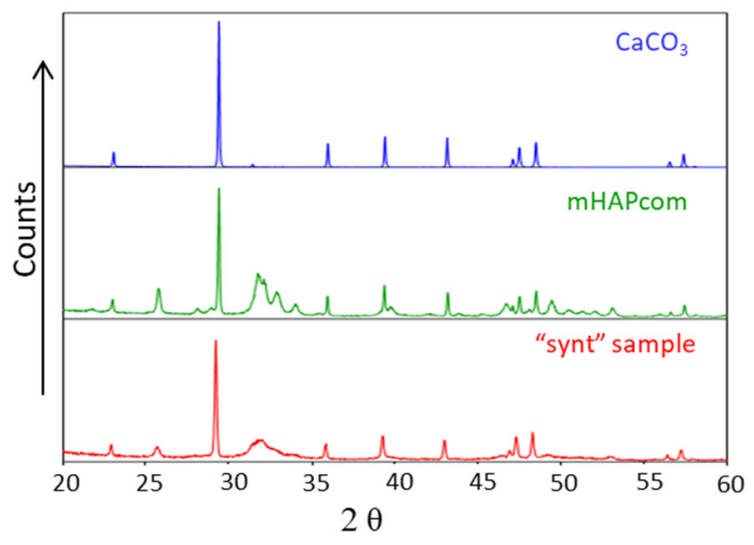

Figure 1. FTIR spectra (a) and the XRD spectra (b) of the selected synthesized material and, for comparison, calcite and a commercial HAP (mHAPcom).

The spectrum of the "synt" sample presented characteristic peaks and bands of HAP: a broad band centred at around $1030 \mathrm{~cm}^{-1}$ (corresponding to asymmetric stretching mode $v_{3}$ of the $\mathrm{PO}_{4}{ }^{3-}$ group) and sharp peaks at 600 and $565 \mathrm{~cm}^{-1}$ (ascribed to bending mode $v_{4}$ of the $\mathrm{PO}_{4}{ }^{3-}$ group). The slight shoulder observed at $964 \mathrm{~cm}^{-1}$ may also be assigned to symmetric stretching mode $v_{1}$ of the $\mathrm{PO}_{4}{ }^{3-}$ group, as well as the broad band observed at $3420 \mathrm{~cm}^{-1}$ which can be ascribed to the stretching vibrations $v(\mathrm{O}-\mathrm{H})$ of the HAP (although it may also be of interstitial water) [35-38]. On the other hand, the characteristic peaks of $\mathrm{CaCO}_{3}$ were also observed: a broad band centred at about $1440 \mathrm{~cm}^{-1}$ (asymmetric stretching $v_{3}$ of $\mathrm{CO}_{3}{ }^{2-}$ ) and well-resolved peaks at $880 \mathrm{~cm}^{-1}$ (out-of-plane bending $v_{2}$ of $\mathrm{CO}_{3}{ }^{2-}$ ) and $715 \mathrm{~cm}^{-1}$ (symmetric in-plane bending $v_{4}$ of $\mathrm{CO}_{3}{ }^{2-}$ ). An additional slight peak at $1810 \mathrm{~cm}^{-1}$ was also observed coming from stretching vibration $v(C=O)$, while the slight shoulder at $1060 \mathrm{~cm}^{-1}$ can be ascribed to symmetrical stretching $v(C-O)[37,39]$. The FTIR spectrum for the "son" sample resembled that of the "synt" sample (not shown).

The XRD spectrum of the "synt" sample presented characteristic diffraction peaks of HAP (e.g., 25.8 and 31. $8^{\circ}$ ) together with those of its precursor $\mathrm{CaCO}_{3}[26,31,40]$. Again, the XRD spectrum for the "son" sample looked like that of the "synt" sample (not shown).

Figure 2 shows the SEM images of the sorbents used in sorption tests. SEM images of the "synt" sample showed that the surface of the calcite MPs was mostly covered by HAP, easily recognizable by its flower-like structure (Figure 2a) [41]. Consistently, EDS analysis confirmed that this layer was constituted by $\mathrm{Ca}, \mathrm{P}$ and $\mathrm{O}$. The layer visible by SEM did not display recognizable individual particles but a continuous coating of aggregated particles instead, making it difficult to assess an average particle size. Very occasional uncoated areas were also observed, exhibiting underlying calcite (with its characteristic layered terraces), as confirmed by EDS analysis (Figure 2b). These bare areas of calcite would help explain the loss of mass $(10 \%)$ observed after the acid attack.

SEM images of the "son" sample seemed to indicate that sonication led to a detachment of HAP, yielding a surface with more bare areas of calcite and more cavities (Figure 2c). The "son" sample also exhibited a highly agglomerated structure. The associated EDS spectrum (not shown) resembled that of the uncovered areas of the "synt" sample (Figure 2b).

SEM images of the commercial macro- and nano-HAP (mHAPcom and nHAPcom, respectively) showed agglomerates of more rounded, smooth HAP particles with different size (of approximately 40 to $60 \mu \mathrm{m}$ ) (Figure 2d,e, respectively). 

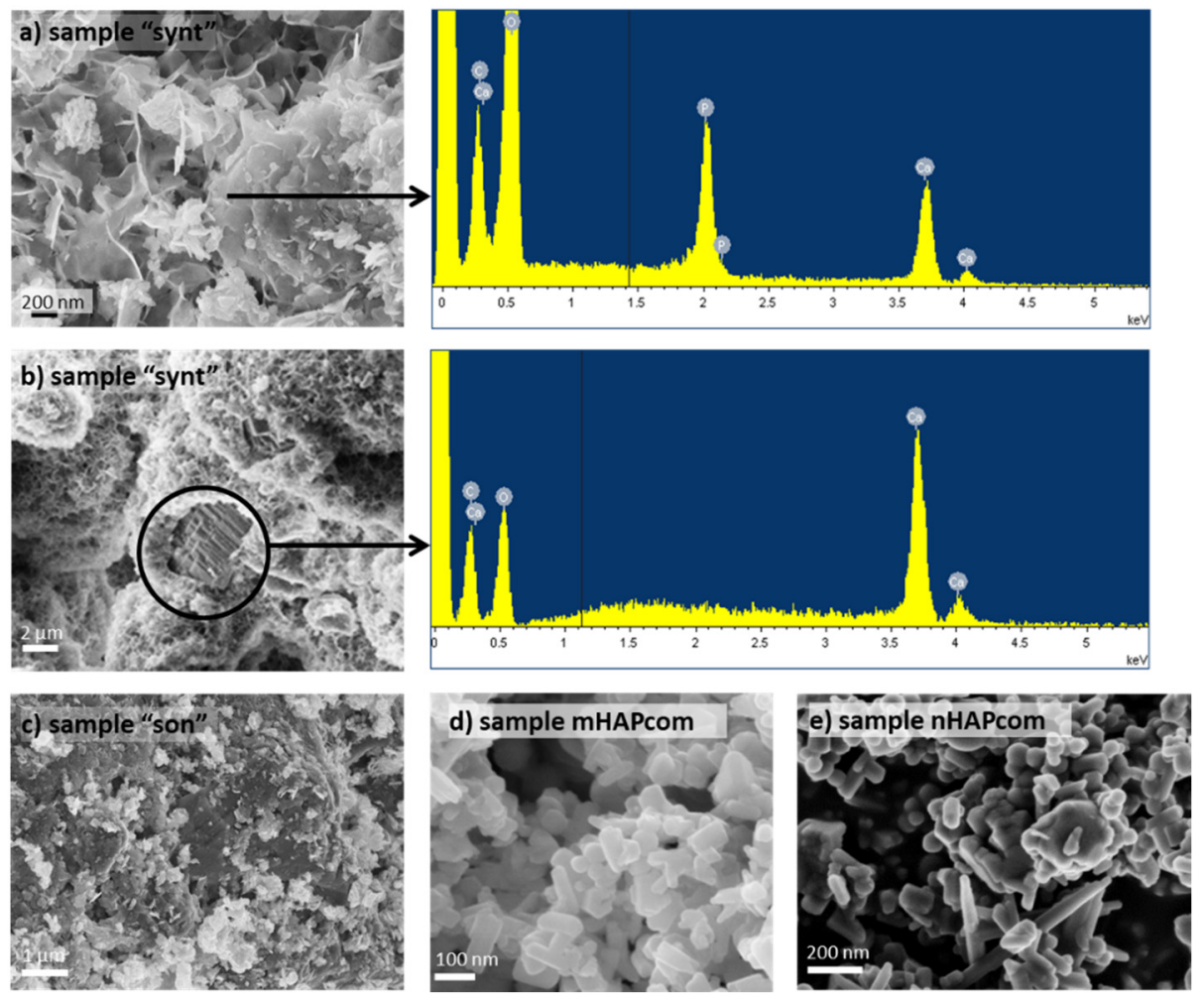

Figure 2. SEM images of the "synt" sample (a,b), "son" sample (c), mHAPcom $(\mathbf{d})$ and nHAPcom (e).

BET results for all studied sorbents are summarized in Table 1. It is worth noting that a notorious specific surface area increment was obtained during the synthesis process from calcite to HAP. Measured values of $\mathrm{S}_{\mathrm{BET}}$ surface areas for "synt" and "son" samples were 58.25 and $53.68 \mathrm{~m}^{2} / \mathrm{g}$, which were similar or slightly lower than that for the mHAPcom $\left(60.77 \mathrm{~m}^{2} / \mathrm{g}\right)$ and clearly higher than that for nHAPcom $\left(18.93 \mathrm{~m}^{2} / \mathrm{g}\right)$. The low value of the latter was probably related to its high crystallinity. The pore volumes of the synthesized HAPs were $0.0016 \mathrm{~cm}^{3} / \mathrm{g}$ for the "synt" sample and $0.0013 \mathrm{~cm}^{3} / \mathrm{g}$ for the "son" sample.

Table 1. Measured values of $S_{B E T}$ surface areas for all studied sorbents.

\begin{tabular}{cc}
\hline Sorbent & $\mathbf{S}_{\mathbf{B E T}}\left(\mathbf{m}^{\mathbf{2}} \mathbf{g}\right)$ \\
\hline Initial calcite & $0.87 \pm 0.01$ \\
\hline Synt & $58.25 \pm 0.08$ \\
Son & $53.68 \pm 0.16$ \\
mHAPcom & $60.77 \pm 0.20$ \\
nHAPcom & $18.93 \pm 0.11$ \\
\hline
\end{tabular}

Volumetric particle size distributions (PSD) of the studied samples are represented in Figure 3. The PSD curve of "synt" and "son" samples exhibited a similar symmetric single peak with distribution widths close to each other, with a shoulder or additional small peak on the right, suggesting that agglomeration of particles took place. However, the two PSDs differed in their mean diameter: $36 \mu \mathrm{m}$ for "synt" and $23 \mu \mathrm{m}$ for "son". This seemed to prove that sonication resulted to some extent in a fracturing or breakage of the agglomerates. For mHAPcom, the PSD curve revealed a mean diameter of $10 \mu \mathrm{m}$, which was apparently smaller than that visualized in SEM analysis (Figure 2d). For nHAPcom, the PSD curve was non-uniform, which indicated that the sample contained particles with very different size (mean diameter of $6 \mu \mathrm{m}$ ). Differences in size between PSD and SEM measurements are usually attributed to agglomeration of particles or inaccuracies in the assumption of sphericity of particles measured in PSD. 


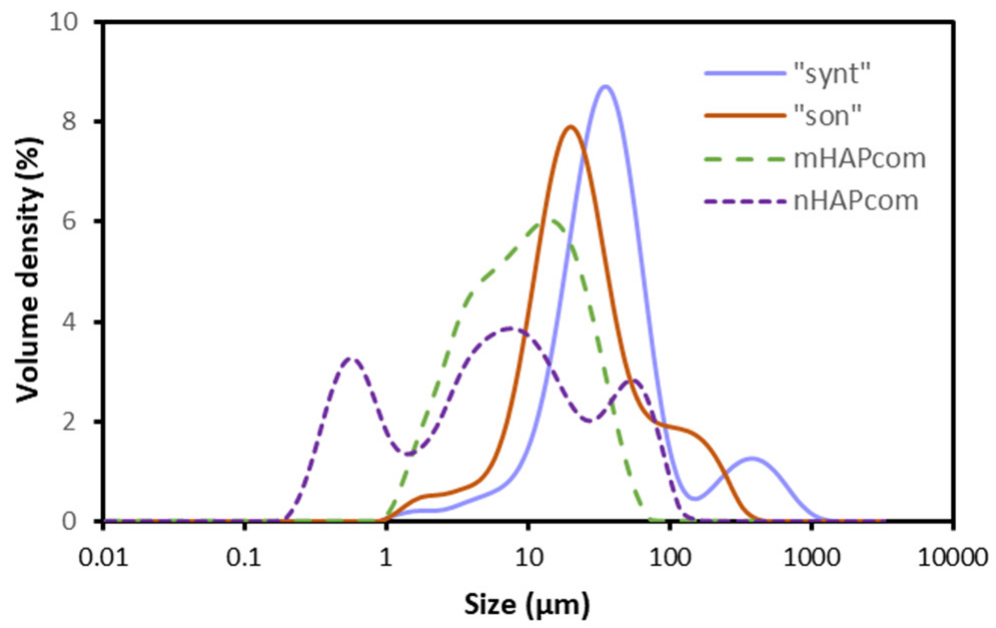

Figure 3. Volumetric particle size distributions (PSD) of samples "synt", "son", mHAPcom and nHAPcom.

The HAP particles synthesized in this study were hence presented as agglomerates of calcite cores coated with HAP of average size of $36 \mu \mathrm{m}$, with a large $S_{\text {BET }}\left(58.25 \mathrm{~m}^{2} / \mathrm{g}\right)$. Sonication of this sample caused some detachment of the HAP layer, resulting in slightly smaller agglomerates (of average size of $23 \mu \mathrm{m})$ and $S_{\text {BET }}\left(53.68 \mathrm{~m}^{2} / \mathrm{g}\right.$ ).

The $\mathrm{pH}_{\text {PZC }}$ was estimated by the immersion technique [34]. Figure 4 represents the change of $\mathrm{pH}(\Delta \mathrm{pH})$ versus the initial $\mathrm{pH}$. The $\mathrm{pH}_{\mathrm{PZC}}$ was identified as the $\mathrm{pH}$ with no variation of $\mathrm{pH}(\Delta \mathrm{pH}=0)$ and quantified to be 7.7 for the "synt" sample and 8.2 for the mHAPcom sample. These values were comparable to reported $\mathrm{pH}_{\mathrm{PZC}}$ for synthesized $\operatorname{HAP}(7.3-8.6)[25,41]$.

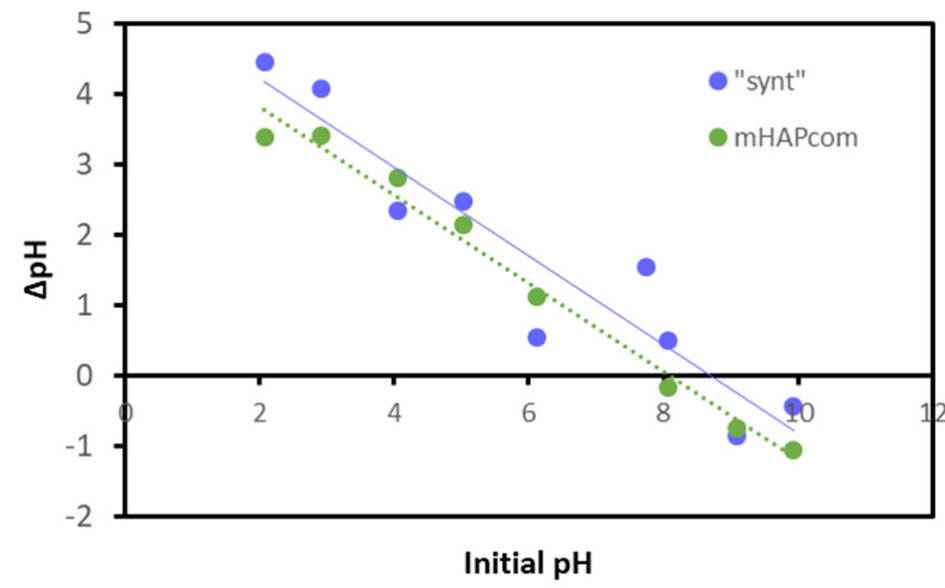

Figure 4. Experimental immersion technique curves corresponding to "synt" and mHAPcom samples for the determination of $\mathrm{pH}_{\mathrm{PZC}}$.

\subsection{Adsorption Kinetics}

Sorption of $\mathrm{Zn}$ and $\mathrm{Cu}$ onto the "synt" sample as a function of time is illustrated in Figure 5. It can be seen that, for both metals, equilibrium between the two phases was attained in approximately $40 \mathrm{~min}$. 


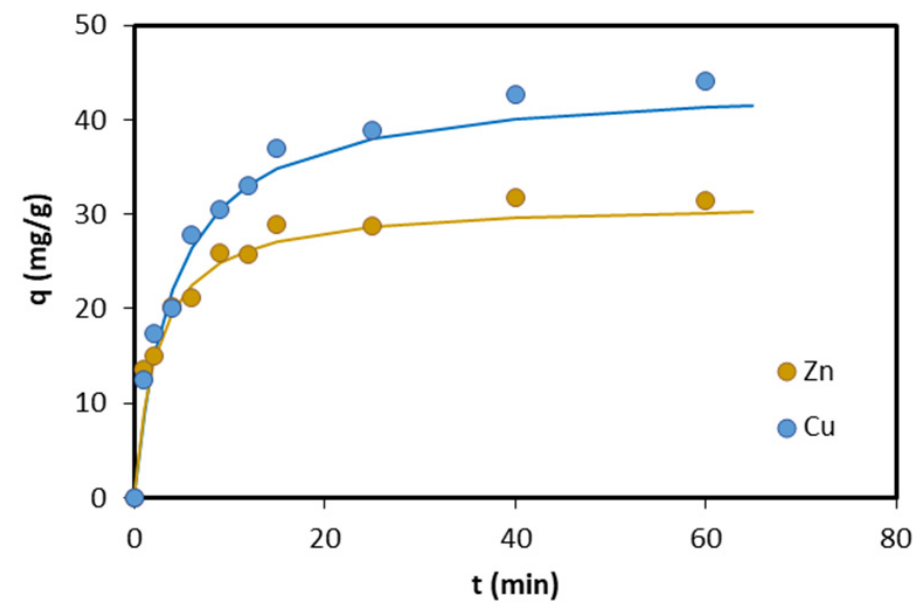

Figure 5. Sorption of $\mathrm{Zn}$ and $\mathrm{Cu}$ onto the synthesized material ("synt" sample) as a function of time. Symbols represent experimental data and fitting lines were plotted using the pseudo-second order kinetic model.

The experimental kinetic data were fitted with pseudo-first and pseudo-second order kinetic equations. The rate constants $\mathrm{k}_{1}$ and $\mathrm{k}_{2}$, and $\mathrm{q}_{\mathrm{e}}$ values were calculated from the interception and slope of the line obtained by plotting $\log \left(\mathrm{q}_{\mathrm{e}}-\mathrm{q}\right)$ and $\mathrm{t} / \mathrm{q}$ against $\mathrm{t}$. The obtained values, together with regression coefficients, are shown in Table 2. The higher regression coefficients for the pseudo-second order kinetic model revealed that this model better described the kinetics of $\mathrm{Zn}$ and $\mathrm{Cu}$ sorption on HAP. The $\mathrm{k}_{2}$ values were found in the range of published values for $\mathrm{Zn}(0.001-0.88 \mathrm{~g} /(\mathrm{mg} \cdot \mathrm{min}))[25,42]$ and $\mathrm{Cu}(0.001-0.076 \mathrm{~g} /(\mathrm{mg} \cdot \mathrm{min}))[36,42-44]$.

Table 2. Comparison of the pseudo-first and pseudo-second order kinetic models for the sorption of $\mathrm{Zn}$ and $\mathrm{Cu}$ onto the synthesized material ("synt" sample).

\begin{tabular}{ccccccc}
\hline Metal & \multicolumn{2}{c}{ Pseudo-First Order Kinetic Model } & \multicolumn{3}{c}{ Pseudo-Second Order Kinetic Model } \\
\hline & $\mathbf{q}_{\mathbf{e}}$ & $\mathbf{k}_{\mathbf{1}}$ & $\mathbf{R}^{\mathbf{2}}$ & $\mathbf{q}_{\mathbf{e}}$ & $\mathbf{k}_{\mathbf{2}}$ & $\mathbf{R}^{\mathbf{2}}$ \\
\hline $\mathrm{Zn}$ & 31.38 & 0.099 & 0.840 & 31.37 & 0.014 & 0.998 \\
\hline $\mathrm{Cu}$ & 44.08 & 0.079 & 0.966 & 44.05 & 0.057 & 0.998 \\
\hline
\end{tabular}

$\mathrm{R}^{2}$ : correlation factor obtained from the linearized from of the kinetic models.

\subsection{Adsorption Isotherms for Single-Metal Solutions}

Figure 6 shows the experimental equilibrium data for the sorption of $\mathrm{Zn}$ and $\mathrm{Cu}$ in single-metal solutions onto "synt", "son", mHAPcom and nHAPcom materials. The fitting of the experimental $c_{e}$ and $q_{e}$ data to the Langmuir-type model gave rise to the values of the constants $\left(\mathrm{q}_{\max }\right.$ and $\left.\mathrm{K}_{\mathrm{L}}\right)$ provided in Table 3. The Langmuir curves generated with the obtained constants are plotted in Figure 6. 
a)

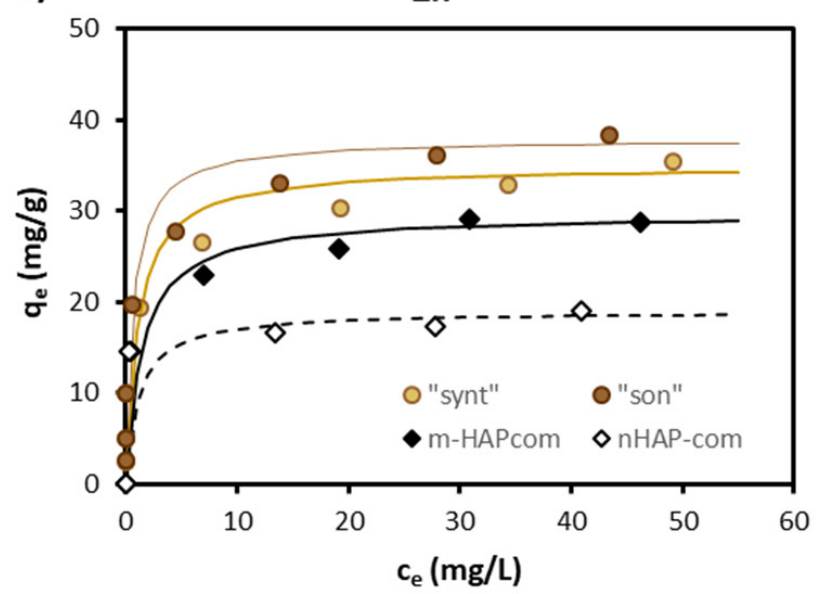

b)

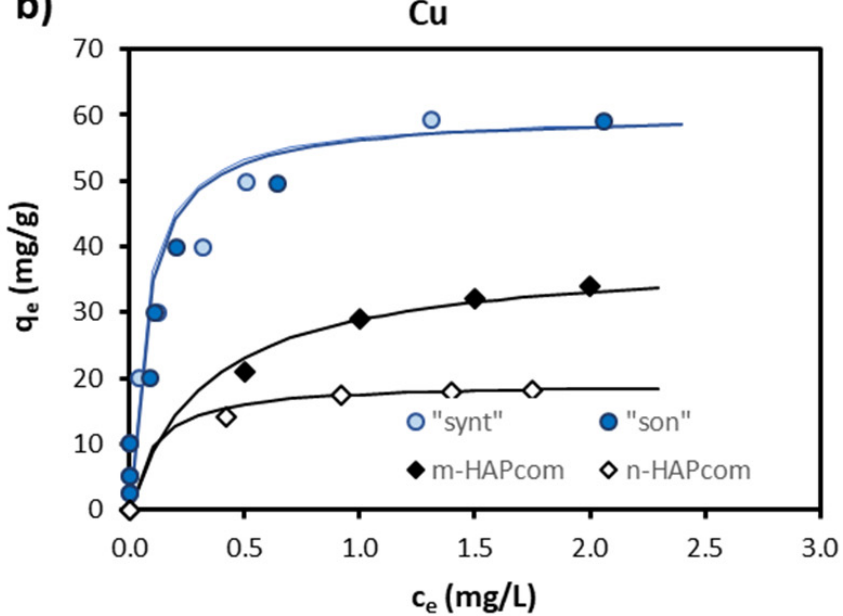

Figure 6. Sorption isotherms for $\mathrm{Zn} \mathrm{(a)} \mathrm{and} \mathrm{Cu}(\mathbf{b})$ onto the sorbents evaluated in this study. Symbols represent experimental data and fitting lines are the isotherms derived from the Langmuir equations.

Table 3. Summary of obtained Langmuir adsorption parameters.

\begin{tabular}{llcccc}
\hline \multirow{2}{*}{ Metal } & \multirow{2}{*}{ Sorbent } & \multicolumn{2}{c}{$\mathbf{q}_{\mathbf{m a x}}$} & $\mathbf{K}_{\mathbf{L}}$ & \multirow{2}{*}{$\mathbf{R}^{\mathbf{2}}$} \\
\cline { 3 - 5 } & Zn & $\mathbf{( m g / g )}$ & $\mathbf{( m g / \mathbf { m } ^ { \mathbf { 2 } }}$ & $\mathbf{( L / m g )}$ & \\
\hline & synt & 34.97 & 0.600 & 0.91 & 0.9978 \\
& son & 37.88 & 0.706 & 1.47 & 0.9984 \\
& mHAPcom & 29.67 & 0.489 & 0.68 & 0.9985 \\
& nHAPcom & 18.98 & 1.003 & 0.85 & 0.9967 \\
\hline $\mathrm{Cu}$ & synt & 60.24 & 1.034 & 15.09 & 0.9905 \\
& son & 60.24 & 1.122 & 13.83 & 0.9955 \\
& mHAPcom & 38.61 & 0.635 & 2.98 & 0.9997 \\
& nHAPcom & 19.27 & 1.018 & 9.88 & 0.9977 \\
\hline
\end{tabular}

The "synt" and "son" materials were efficient in sorbing Zn ( $\left.q_{\max }=34.97-37.88 \mathrm{mg} / \mathrm{g}\right)$ and $\mathrm{Cu}\left(\mathrm{q}_{\max }=60.24 \mathrm{mg} / \mathrm{g}\right)$, with sorption capacities higher than those of commercial HAPs (Figure 5) (note that isotherms for Cu on both "synt" and "son" sorbents in Figure 6b superpose in the whole concentration range). Considering that sorption is a surficial process, $\mathrm{q}_{\max }$ were $\mathrm{S}_{\mathrm{BET}}$-normalized. As can be seen in Table 3, the obtained values were still higher for the synthesized materials (excepting for $\mathrm{Zn}$ on nHAPcom).

Table 4 compares $q_{\max }$ obtained in this study with reported values in the literature. It must be kept in mind that sorption capacity of a given HAP largely depends on the conditions of its preparation and sorption experiments' conditions. Therefore, Table 4 only compares studies on HAP synthesized through wet chemical precipitation and evaluated in batch sorption tests. As can be seen, values of $\mathrm{q}_{\max }$ in this study were comparable to published values. In general, more crystalline HAP yielded lower $\mathrm{q}_{\max }$ but also lower $\mathrm{S}_{\mathrm{BET}}$, so that $\mathrm{S}_{\mathrm{BET}}$-normalized $\mathrm{q}_{\max }$ remained almost constant, as also observed by Šljivić et al. [43]. 
Table 4. Comparison of Langmuir sorption parameters against previous studies with synthesized HAP through wet chemical precipitation.

\begin{tabular}{|c|c|c|c|c|c|c|c|c|c|}
\hline \multirow{2}{*}{\multicolumn{4}{|c|}{ HAP Synthesis and Characteristics }} & \multicolumn{5}{|c|}{ Adsorption } & \multirow{3}{*}{ Ref } \\
\hline & & & & \multicolumn{3}{|c|}{$\mathrm{Zn}$} & \multicolumn{2}{|c|}{$\mathrm{Cu}$} & \\
\hline Precursors & $\mathrm{pH}$ & $\mathbf{T}$ & $\begin{array}{c}\mathrm{S}_{\mathrm{BET}} \\
\left(\mathrm{m}^{2} / \mathrm{g}\right)\end{array}$ & $\mathrm{pH}$ & $\underset{(\mathrm{mg} / \mathrm{g})}{\mathrm{q}_{\max }}$ & $\underset{\left(\mathrm{mg} / \mathrm{m}^{2}\right)}{\mathrm{q}_{\max }}$ & $\underset{(\mathrm{mg} / \mathrm{g})}{\mathrm{q}_{\max }}$ & $\underset{\left(\mathrm{mg} / \mathrm{m}^{2}\right)}{\mathrm{q}_{\max }}$ & \\
\hline $\mathrm{Ca}(\mathrm{OH})_{2}+\mathrm{H}_{3} \mathrm{PO}_{4}$ & n.r. & 20 & 67 & 5.0 & 37.53 & 0.560 & - & - & [25] \\
\hline $\begin{array}{l}\mathrm{Ca}\left(\mathrm{NO}_{3}\right)_{2}+ \\
\left(\mathrm{NH}_{4}\right) \mathrm{HPO}_{4} \\
\left(+\mathrm{Fe}_{3} \mathrm{O}_{4} / \mathrm{Fe}_{2} \mathrm{O}_{3}\right)\end{array}$ & 11 & 90 & 142.5 & $5.0^{(\mathrm{a})}$ & $140.6^{(b)}$ & 0.99 & - & - & [45] \\
\hline $\mathrm{Ca}(\mathrm{OH})_{2}+\mathrm{H}_{3} \mathrm{PO}_{4}$ & n.r & 100 & 76.6 & $\begin{array}{l}6.0^{(\mathrm{a})} \\
5.5^{(\mathrm{a})}\end{array}$ & $\begin{array}{c}102.04 \\
37.27\end{array}$ & $\begin{array}{l}1.332 \\
0.750\end{array}$ & $\begin{array}{l}- \\
-\end{array}$ & $\begin{array}{l}- \\
-\end{array}$ & [35] \\
\hline $\begin{array}{l}\mathrm{Ca}\left(\mathrm{NO}_{3}\right)_{2}+ \\
\left(\mathrm{NH}_{4}\right)_{2} \mathrm{HPO}_{4}\end{array}$ & 11 & n.r. & n.r. & $5.0^{(\mathrm{a})}$ & 10.75 & n.r. & - & - & [36] \\
\hline commercial & & & 77 & 6.0 & 37.14 & 0.482 & - & - & [46] \\
\hline commercial & & & 50 & 6.6 & 95.89 & 1.92 & 76.49 & 1.53 & [42] \\
\hline $\begin{array}{l}\mathrm{CaCl}_{2}+\mathrm{NH}_{4} \mathrm{H}_{2} \mathrm{PO}_{4}+ \\
\mathrm{EtOH}\left(+\mathrm{Fe}_{3} \mathrm{O}_{4}\right)\end{array}$ & 11 & 20 & 101.2 & $5.0^{(\mathrm{a})}$ & - & - & 48.78 & 0.482 & [18] \\
\hline $\mathrm{Ca}(\mathrm{OH})_{2}+\mathrm{H}_{3} \mathrm{PO}_{4}$ & n.r. & n.r & 58 & 5.0 & - & - & 37.17 & 0.641 & [43] \\
\hline \multirow{2}{*}{$\begin{array}{l}\mathrm{Ca}\left(\mathrm{NO}_{3}\right)_{2}+\mathrm{H}_{3} \mathrm{PO}_{4}+ \\
\mathrm{NH}_{4}^{+} \text {-salt }\end{array}$} & \multirow{2}{*}{10} & \multirow{2}{*}{40} & \multirow{2}{*}{49.7} & $4.5^{(\mathrm{a})}$ & - & - & 29.23 & 0.588 & \multirow{2}{*}{ [44] } \\
\hline & & & & $5.5^{(a)}$ & - & - & 37.30 & 0.751 & \\
\hline $\begin{array}{l}\text { Calcite }+\left(\mathrm{NH}_{4}\right)_{2} \mathrm{PO}_{4} \\
(+\mathrm{EtOH})\end{array}$ & \multirow{3}{*}{8} & \multirow{3}{*}{25} & 58.28 & 4.6 & 34.97 & 0.600 & 60.24 & 1.034 & \multirow{4}{*}{$\begin{array}{l}\text { This } \\
\text { study }\end{array}$} \\
\hline $\begin{array}{l}\text { Calcite }+\left(\mathrm{NH}_{4}\right)_{2} \mathrm{PO}_{4} \\
(+ \text { EtOH })(+ \text { sonication })\end{array}$ & & & 53.68 & 4.6 & 37.88 & 0.706 & 60.24 & 1.122 & \\
\hline Commercial (mHAPcom) & & & 60.77 & 4.6 & 29.67 & 0.489 & 38.61 & 0.635 & \\
\hline Commercial (nHAPcom) & & & 18.93 & 4.6 & 18.98 & 1.003 & 19.27 & 0.985 & \\
\hline
\end{tabular}

n.r.: not reported. ${ }^{(a)} \mathrm{pH}$ maintained constant. ${ }^{(b)}$ Read from Figure 5 in Feng et al. [45].

Some authors have explained the difference in selectivity of HAP toward different metal cations on the basis of their hydrated ion radius and electronegativity [25]. The higher hydrated ion radius ( $4.30 \AA$ ) and lower electronegativity (1.60) of $\mathrm{Zn}$ than of $\mathrm{Cu}$ (4.19 and $1.90 \AA$, respectively) and their sorption extent observed in the present study seemed to support this theory.

\subsection{Sorption Mechanisms}

Figure 7 shows that $\mathrm{Zn}$ and $\mathrm{Cu}$ sorption was accompanied by a pH decrease (Figure 7a,c) and an increase of $\mathrm{Ca}^{2+}$ concentration in the solution (Figure $7 \mathrm{~b}, \mathrm{~d}$ ). Both were proportional to the amount of $\mathrm{Zn}$ and $\mathrm{Cu}$ sorbed onto $\operatorname{HAP}\left(\mathrm{q}_{\mathrm{e}}\right)$.

The $\mathrm{pH}$ decrease can be explained by the surface complexation reaction between $\mathrm{Zn}$ and $\mathrm{Cu}$ and deprotonated surface hydroxyls of HAP, summarized as follows [42,47]:

$$
\begin{aligned}
& \equiv \mathrm{HAP}-\mathrm{OH}+\mathrm{M}^{2+} \leftrightarrows \equiv \mathrm{HAP}-\mathrm{O}-\mathrm{M}^{+}+\mathrm{H}^{+} \\
2 & \equiv \mathrm{HAP}-\mathrm{OH}+\mathrm{M}^{2+} \leftrightarrows(\equiv \mathrm{HAP}-\mathrm{O}) 2 \mathrm{M}+2 \mathrm{H}^{+}
\end{aligned}
$$

where $\mathrm{M}^{2+}$ stands for $\mathrm{Zn}^{2+}$ or $\mathrm{Cu}^{2+}$ ions. Decreases of $\mathrm{pH}$ by metal sorption on HAP have also been observed by other investigators $[18,25,35,43]$. In the absence of $\mathrm{M}^{2+}$, the $\mathrm{pH}$ in the present study increased from the initial $\mathrm{pH} 4.7$ to 9.2. Unlike other studies, this increase was beyond $\mathrm{pH}_{\mathrm{PZC}}$ of HAP (in the range 6.1-8.3) $[18,36,43]$, probably because calcite in bare areas of the HAP-coated calcite MPs dissolved and caused $\mathrm{pH}$ to rise to higher values than HAP alone would do. It is worth noting that as long as $\mathrm{pH}$ remained above $\mathrm{pH}_{\mathrm{PZC}}$ 
(i.e., the HAP surface exhibited a negative charge), electrostatic forces between the HAP surface and the metal cation favored cation sorption [48].

a)
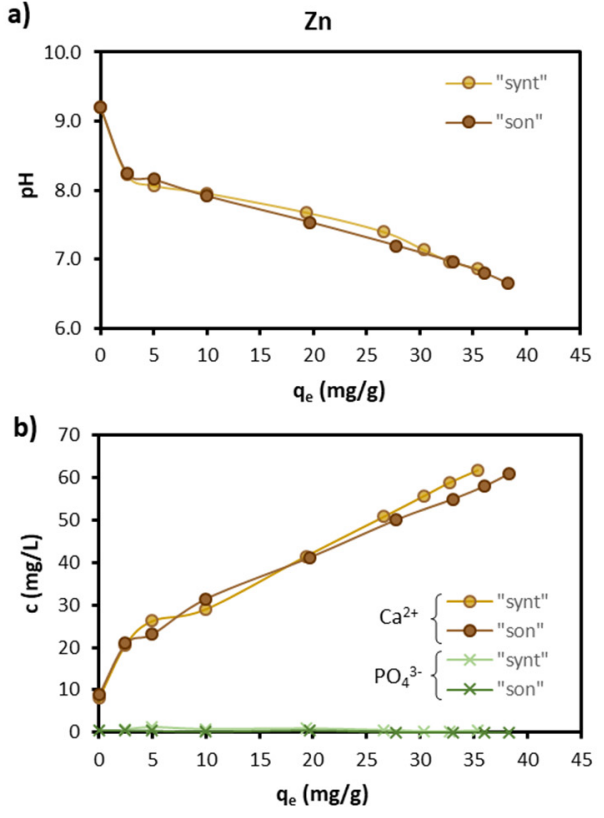

c)

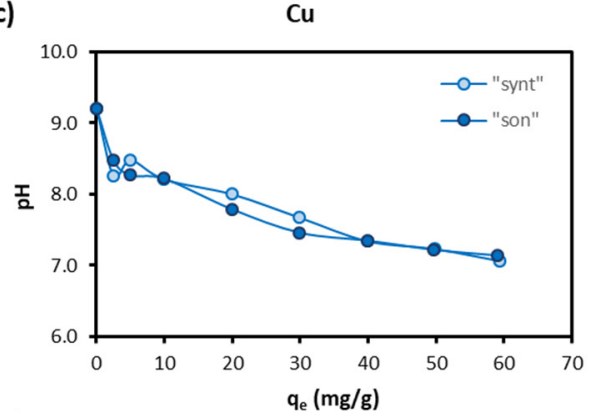

d)

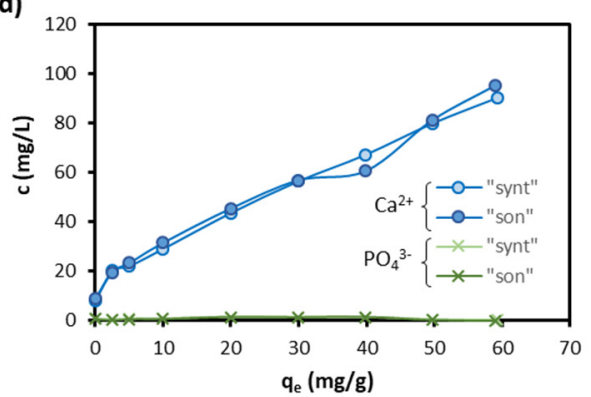

Figure 7. Variations in $\mathrm{pH}$ and $\mathrm{Ca}^{2+}$ and $\mathrm{PO}_{4}{ }^{3-}$ concentrations following $\mathrm{Zn}$ sorption (a,b, respectively) and $\mathrm{Cu}(\mathrm{c}, \mathrm{d}$, respectively) sorption.

However, the simple surface complexation process would not cause any $\mathrm{Ca}^{2+}$ concentration. The increase in $\mathrm{Ca}^{2+}$ concentration was fairly well-explained by an ion exchange process, whereby $\mathrm{M}^{2+}$ replaces a surface $\mathrm{Ca}^{2+}$ of the HAP, presented as follows:

$$
\equiv \mathrm{HAP}-\mathrm{Ca}^{2+}+\mathrm{M}^{2+} \leftrightarrows \equiv \mathrm{HAP}-\mathrm{M}^{2+}+\mathrm{Ca}^{2+}
$$

Increases in $\mathrm{Ca}^{2+}$ concentration from ion exchange on HAP have previously been reported $[18,25,42]$.

Figure 8 presents the relationship between the number of moles of released $\mathrm{Ca}^{2+}$ versus the number of moles of adsorbed $\mathrm{Zn}$ (Figure $8 \mathrm{a}$ ) and $\mathrm{Cu}$ (Figure $8 \mathrm{~b}$ ). The relationship is linear with a slope very close to unity. A slope close to unity would suggest that $\mathrm{Zn}$ and $\mathrm{Cu}$ were removed solely by ion exchange.
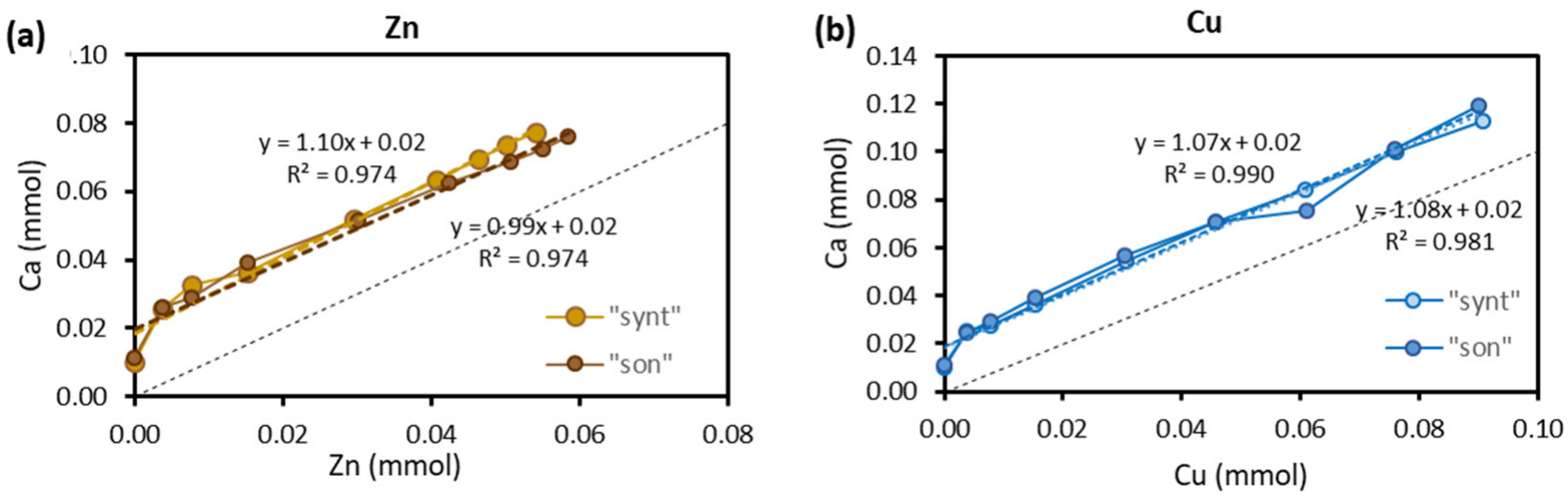

Figure 8. Relationship between the number of moles of released $\mathrm{Ca}^{2+}$ vs the number of moles of adsorbed $\mathrm{Zn}(\mathbf{a})$ and $\mathrm{Cu}(\mathbf{b})$.

Nevertheless, the decrease of $\mathrm{pH}$ seen above revealed that ion exchange could not be the unique mechanism behind the metal removal. Therefore, other mechanisms also 
took place besides ion exchange that explained the $\mathrm{Ca}^{2+}$ release. $\mathrm{Ca}^{2+}$ release might also be due to exposed calcite dissolution, which was favored as $\mathrm{pH}$ decreased (from 9.2 to 7.0) as metal sorbed onto HAP (Figure 7). Ca concentration value on the y-axis (i.e., in the absence of metal sorption) would support this hypothesis. Another source that might contribute to the $\mathrm{Ca}^{2+}$ release (although to a limited extent) was HAP dissolution. Crystalline HAP dissolution is reported to occur generally at $\mathrm{pH}<5$, but non-crystalline and substituted with $\mathrm{Ca}^{2+} \mathrm{HAP}$ (as it might be the case in this study as HAP was synthesized from calcite dissolution) may dissolve at higher $\mathrm{pH}[30,49] . \mathrm{Ca}^{2+}$ concentrations in equilibrium with HAP have been reported to range from $1.4 \mathrm{mg} / \mathrm{L}$ for highly crystalline HAP to $7.5 \mathrm{mg} / \mathrm{L}$ for poorly crystalline HAP [49]. That being the case, the insignificant concentration of $\mathrm{PO}_{4}{ }^{3-}$ (Figure 7) would indicate precipitation of $\mathrm{PO}_{4}{ }^{3-}$-bearing solid phases. Metal precipitation with $\mathrm{PO}_{4}{ }^{3-}$ released from HAP dissolution has been observed $[18,42,50]$.

Precipitation, and not only of $\mathrm{PO}_{4}{ }^{3-}$-bearing solid phases, is in fact a third mechanism that is expected to contribute to the overall removal of $\mathrm{Zn}$ and $\mathrm{Cu}$. Speciation diagrams based on thermodynamic equilibria in $\mathrm{Zn}$ and $\mathrm{Cu}$ systems at $\mathrm{pH}$ 6.5-8 in the presence of $\mathrm{CO}_{3}{ }^{2-}$ (from calcite) and $\mathrm{PO}_{4}{ }^{3-}$ (from HAP) anticipate the formation of non-soluble phases such as $\mathrm{Zn}_{3}\left(\mathrm{PO}_{4}\right)_{2} \cdot 4 \mathrm{H}_{2} \mathrm{O}(\mathrm{s})$ for $\mathrm{Zn}$ and $\mathrm{Cu}_{3}\left(\mathrm{PO}_{4}\right)_{2}(\mathrm{~s})$ and $\mathrm{Cu}_{2} \mathrm{CO}_{3}(\mathrm{OH})_{2}(\mathrm{~s})$ for $\mathrm{Cu}$ (Figure 9).

a)

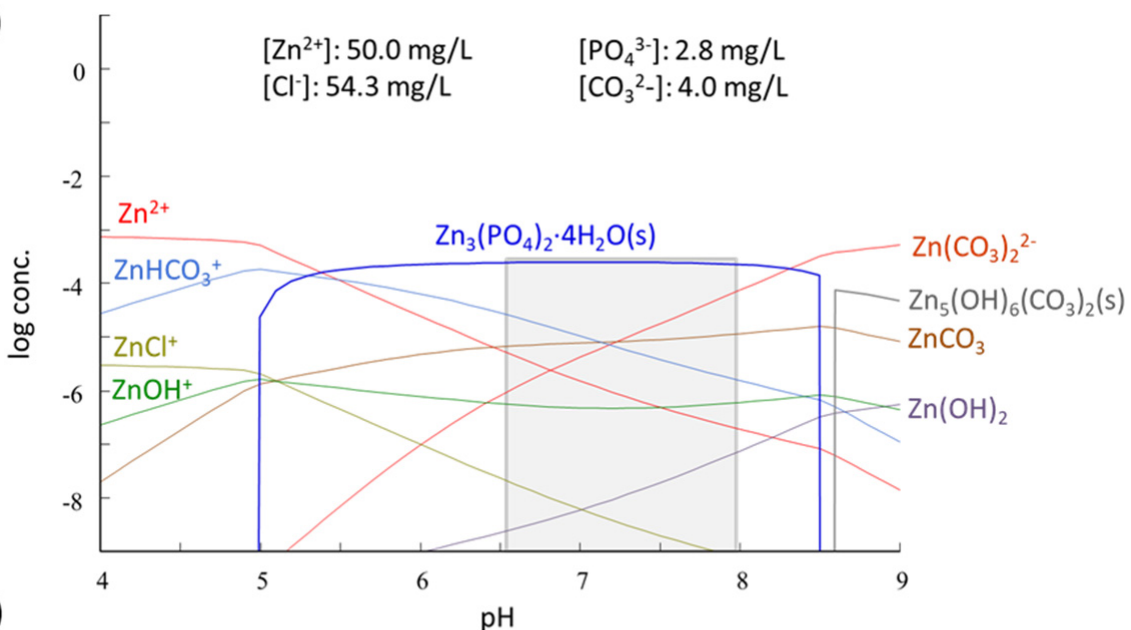

b)

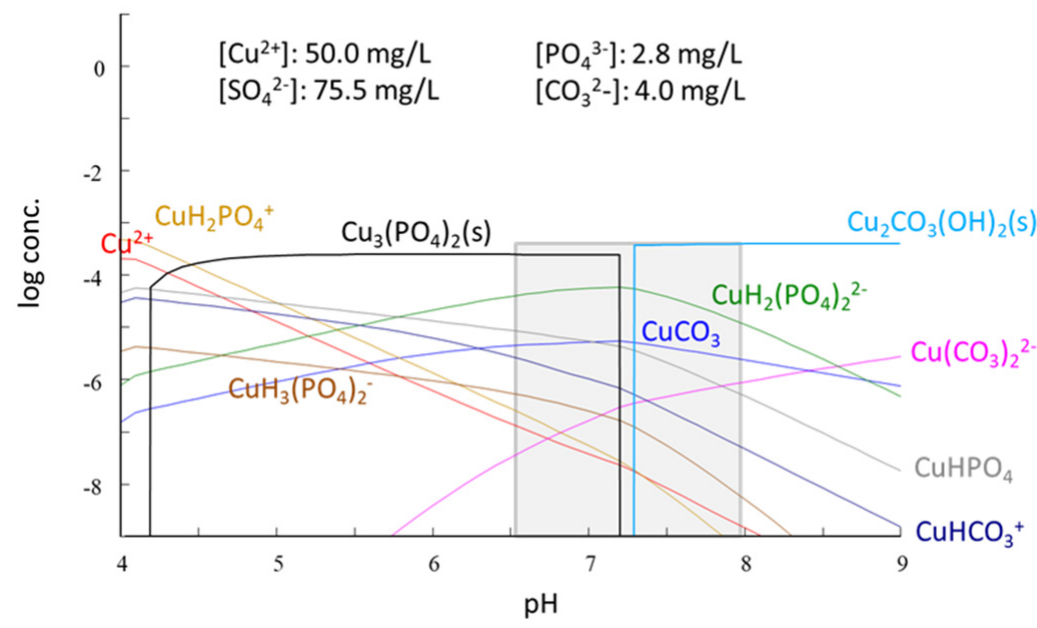

Figure 9. Species distribution diagram as a function of $\mathrm{pH}$ for (a) $\mathrm{Zn}$ and (b) $\mathrm{Cu}$ with a total metal concentration of $50 \mathrm{mg} / \mathrm{L}$ in a matrix representative of the supernatants containing the counter-ion in the metal salt $\left(\mathrm{Cl}^{-}\right.$for $\mathrm{Zn}$ and $\mathrm{SO}_{4}{ }^{2-}$ for $\left.\mathrm{Cu}\right), \mathrm{CO}_{3}{ }^{2-}$ and $\mathrm{PO}_{4}{ }^{3-}$. Minor species are not shown. The grey bars indicate the $\mathrm{pH}$ value of experiments. Distribution diagrams have been plotted using the software packages Hydra and Medusa [51]. 
XRD analysis performed on HAP loaded with $\mathrm{Zn}$ and $\mathrm{Cu}$ from the sorption experiments did not offer any peak attributable to new phases (not shown), probably due to their low crystallinity. However, XRD analysis of these samples after calcination at $700{ }^{\circ} \mathrm{C}$ for $3 \mathrm{~h}$ revealed the appearance of peaks associated to $\mathrm{Zn}_{3}\left(\mathrm{PO}_{4}\right)_{2} \cdot 4 \mathrm{H}_{2} \mathrm{O}$ (hopeite) for $\mathrm{Zn}$, and to $\mathrm{Cu}_{3}\left(\mathrm{PO}_{4}\right)_{2}$ for $\mathrm{Cu}$ (Figure 10). The appearance of these peaks confirmed the precipitation of $\mathrm{Zn}$ and $\mathrm{Cu}$ in the form of phosphates (it must be kept in mind that calcination might have altered the precipitated new phases, e.g., decarbonation by loss of $\mathrm{CO}_{2}$, and that the observed phases by XRD can be only a part of the precipitated phases). Hopeite formation in sorption experiments of Zn onto HAP has also been observed by Stötzel et al. [50] and Sheha [35]. Although not in the present study, hydrozincite has also been detected by Sheha [35] and Meski et al. [36]. With regard to $\mathrm{Cu}, \mathrm{Cu}(\mathrm{OH})_{2}$ and $\mathrm{Cu}_{2}\left(\mathrm{PO}_{4}\right)(\mathrm{OH})$ (libethenite) have been detected by Šljivić et al. [43].

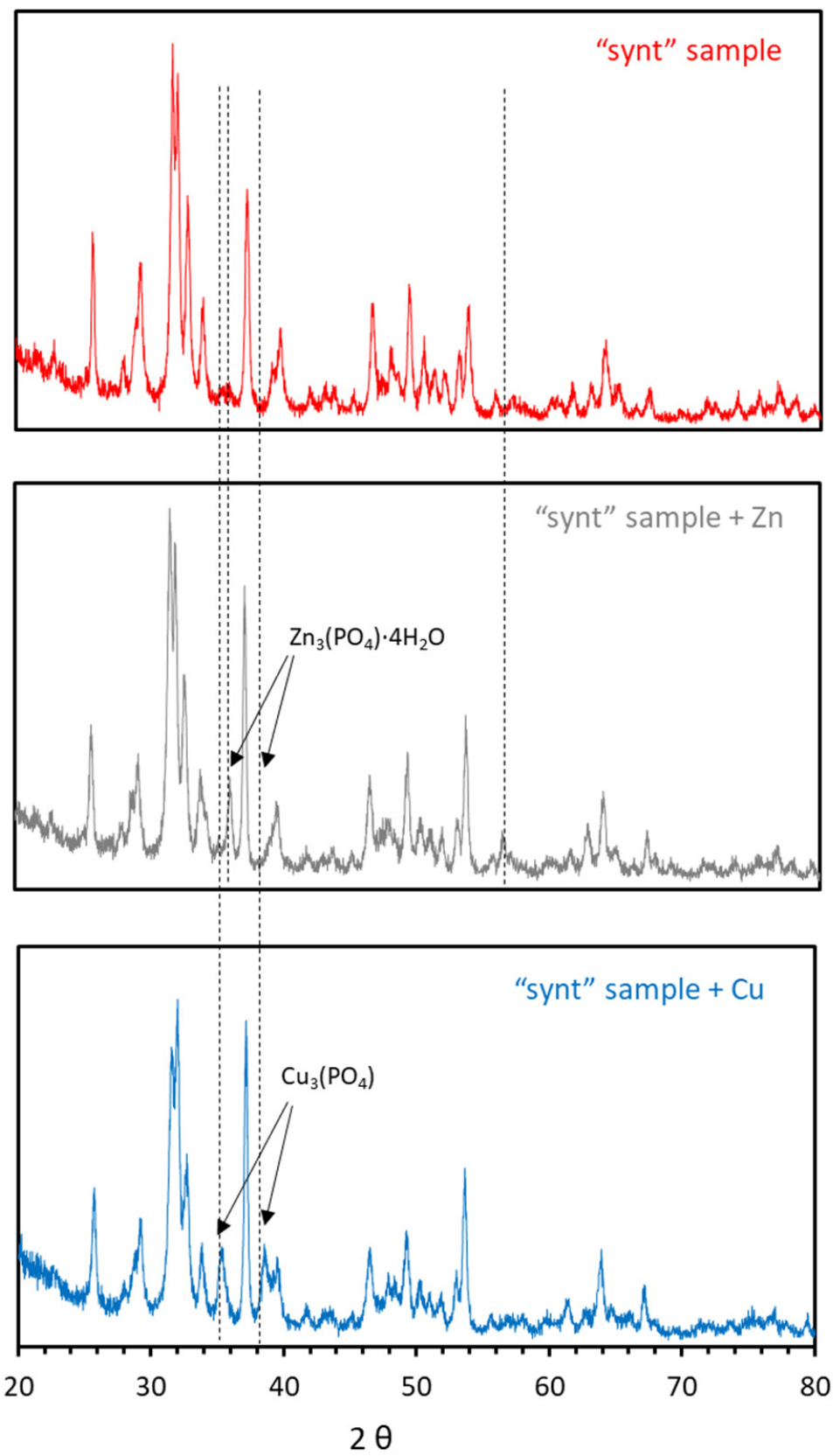

Figure 10. XRD patterns of the synthesized material after contact with $\mathrm{Zn}$ and $\mathrm{Cu}$. 
Further experiments were performed to experimentally confirm the occurrence of $\mathrm{Zn}$ and $\mathrm{Cu}$ precipitation in the studied conditions. With the purpose of isolating the eventual precipitation mechanism, HAP amounts $(0.1 \mathrm{~g})$ were weighted and equilibrated with deionized water $(50 \mathrm{~mL})$ at $\mathrm{pH} 4.25$ for $24 \mathrm{~h}$. Afterwards, the generated lixiviates were filtrated, and then, in the absence of HAP (i.e., without the possibility of sorption occurrence), $\mathrm{Zn}$ (or $\mathrm{Cu}$ ) was added to achieve a final metal concentration of $50 \mathrm{mg} / \mathrm{L}$. $\mathrm{pH}$ was adjusted to achieve different final values of 2.2, 6.7 and 8.0. Under these conditions, any disappearance of metal from the solution could only be attributed to precipitation. The analyses showed that at $\mathrm{pH} 2.2$, neither $\mathrm{Zn}$ nor $\mathrm{Cu}$ were barely removed $(<5 \%)$, but $\mathrm{Zn}$ was removed by $33 \%$ at $\mathrm{pH} 6.7$ and by $99 \%$ at $\mathrm{pH} 8.0$, while $\mathrm{Cu}$ was removed by $97 \%$ at $\mathrm{pH} 6.7$ and $>99 \%$ at $\mathrm{pH}$ 8.0. These findings were in agreement with the $\mathrm{Zn}$ and $\mathrm{Cu}$ speciation diagrams (Figure 9), except for $\mathrm{Zn}$ at $\mathrm{pH}$ 6.7, for which the observed removal was lower than the theoretical one.

\section{Conclusions}

Calcite MPs were efficiently coated with a HAP layer following a synthesis route based on two successive precipitations of HAP, with the first involving ethanol $0.5 \%$. Since bare areas of calcite occurred, at $\mathrm{pH} 4.6$ (that of the water to be treated), calcite partially dissolved, raising $\mathrm{pH}$ to values $>9$. The synthesized material showed high capacity in sorbing $\mathrm{Zn}$ and $\mathrm{Cu}$ from acidic solutions, making it potentially attractive for the removal of divalent heavy metals from contaminated water. The sorption isotherm was well fitted by the Langmuir model, with $\mathrm{q}_{\max }$ of $34.97 \mathrm{mg} / \mathrm{g}$ for $\mathrm{Zn}$ and $60.24 \mathrm{mg} / \mathrm{g}$ for $\mathrm{Cu}$, indicating more affinity of HAP towards $\mathrm{Cu}$ than towards $\mathrm{Zn}$. Sorption of $\mathrm{Zn}$ and $\mathrm{Cu}$ onto the synthesized HAP followed a pseudo-second order kinetics, with $\mathrm{k}_{2}$ of $0.014 \mathrm{~g} /(\mathrm{mg} \cdot \mathrm{min})$ for $\mathrm{Zn}$ and $0.057 \mathrm{~g} /(\mathrm{mg} \cdot \mathrm{min})$ for $\mathrm{Cu}$. On the other hand, sonication of the synthesized material seemed to lead to some breakage of agglomerated particles (decrease of mean diameter agglomerate from 36 to $23 \mu \mathrm{m}$ ), which resulted in a slight increase of $\mathrm{q}_{\max }$ for $\mathrm{Zn}$ $(37.88 \mathrm{~g} / \mathrm{mg})$ without affecting that of $\mathrm{Cu}$. The mechanisms behind the sorption of $\mathrm{Zn}$ and $\mathrm{Cu}$ onto HAP were diverse and mainly included surface complexation, ion exchange and precipitation of new $\mathrm{Zn}$ - and $\mathrm{Cu}$-containing phases. These mechanisms acted together, and it was difficult to quantitatively estimate the contribution of each of them to the overall removal of $\mathrm{Zn}$ and $\mathrm{Cu}$.

In view of this performance, we anticipate that the HAP-coated calcite MPs prepared in this study have the potential to remediate heavy metal-contaminated water in ex-situ and, more promisingly, in-situ treatments. When injected into the subsoil for in-situ treatment, these HAP-coated calcite MPs may avoid complications that other MPs and NPs aiming at the removal of heavy metals face, as reported by the relatively abundant fundamental research but also by the currently scarce experience in field applications. In fact, NPs based on carbonaceous materials do not always exhibit high metal sorption capacities unless they are functionalized, while zero-valent iron NPs have a strong tendency to aggregate, which hinders their migration through the contaminated plume, and to have their surface passivated by precipitated of $\mathrm{Fe}$-(oxy)hydroxide, which limits the reactivity of zero-valent iron. Despite this anticipated advantage of HAP-based particles, the limited availability of reports on their application for the removal of heavy metals from water makes further studies necessary, both at laboratory and field scales, before drawing major conclusions on the remediation constraints and environmental implications of their application.

On the other hand, it is acknowledged that one problem of NPs is the relatively high cost of synthesizing them. In this sense, and as an innovative aspect of the study, the synthesis route of HAP (based on solid calcite contacted with a phosphate solution instead of the conventional and widely employed wet chemical precipitation, which is based on the use of soluble $\mathrm{Ca}^{2+}$-salts) can allow to save huge amounts of soluble Ca-chemicals and make the process more cost-efficient and improve its competitiveness. 
Author Contributions: Conceptualization: O.G., V.M., C.V. and M.M.M.; Methodology: O.G. and V.M.; Formal analysis: V.M. and R.M.D.; Investigation: V.M. and M.M.M.; Resources: O.G. and V.M.; Data curation: O.G., V.M., C.V., M.M.M. and R.M.D.; Writing-Original draft preparation: O.G.; Writing-Review and editing: V.M., C.V. and J.O.M.; Supervision: V.M. and J.O.M.; Funding acquisition: V.M. All authors have read and agreed to the published version of the manuscript.

Funding: This work was funded by the Spanish Ministry of Science, Innovation and Universities and European Funds FEDER (AEI/FEDER) through the project NANOREMOV (CGL2017-87216-C4-3-R). Financial support was also received from the Agency for University Grants Administration and Research (AGAUR) of the Catalan Government through the Research Groups Support program (2014-SGR-050).

Institutional Review Board Statement: Not applicable.

Informed Consent Statement: Not applicable.

Data Availability Statement: The data presented in this study is available on request from the corresponding author.

Acknowledgments: The authors thank A. Marín, R. Ramos and A. Guillaumet for their laboratory assistance.

Conflicts of Interest: The authors declare no conflict of interest.

\section{References}

1. Burri, N.M.; Weatherl, R.; Moeck, C.; Schirmer, M. A review of threats to groundwater quality in the Anthropocene. Sci. Total Environ. 2019, 684, 136-154. [CrossRef]

2. Zhou, P.; Adeel, M.; Shakoor, N.; Guo, M.; Hao, Y.; Azeem, I.; Li, M.; Liu, M.; Rui, Y. Application of nanoparticles alleviates heavy metals stress and promotes plant growth: An overview. Nanomaterials 2021, 11, 26. [CrossRef]

3. Vareda, J.P.; Valente, A.J.M.; Durães, L. Assessment of heavy metal pollution from anthropogenic activities and remediation strategies: A review. J. Environ. Manag. 2019, 246, 101-118. [CrossRef]

4. Vidu, R.; Matei, E.; Predescu, A.M.; Alhalaili, B.; Pantilimon, C.; Tarcea, C.; Predescu, C. Removal of heavy metals from wastewaters: A challenge from current treatment methods to nanotechnology applications. Toxics 2020, 8, 101. [CrossRef]

5. Carolin, C.F.; Kumar, P.S.; Saravanan, A.; Joshiba, G.J.; Naushad, M. Efficient techniques for the removal of toxic heavy metals from aquatic environment: A review. J. Environ. Chem. Eng. 2017, 5, 2782-2799. [CrossRef]

6. Abdullah, N.; Yusof, N.; Lau, W.J.; Jaafar, J.; Ismail, A.F. Recent trends of heavy metal removal from water/wastewater by membrane technologies. J. Ind. Eng. Chem. 2019, 76, 17-38. [CrossRef]

7. Kaushik, A.; Singh, A. Metal removal and recovery using bioelectrochemical technology: The major determinants and opportunities for synchronic wastewater treatment and energy production. J. Environ. Manag. 2020, 270, 110826. [CrossRef] [PubMed]

8. Malik, L.A.; Bashir, A.; Qureashi, A.; Pandith, A.H. Detection and removal of heavy metal ions: A review. Environ. Chem. Lett. 2019, 17, 1495-1521. [CrossRef]

9. Waheed, A.; Baig, N.; Ullah, N.; Falath, W. Removal of hazardous dyes, toxic metal ions and organic pollutants from wastewater by using porous hyper-cross-linked polymeric materials: A review of recent advances. J. Environ. Manag. 2021, $287,112360$. [CrossRef] [PubMed]

10. Adeleye, A.S.; Conway, J.R.; Garner, K.; Huang, Y.; Su, Y.; Keller, A.A. Engineered nanomaterials for water treatment and remediation: Costs, benefits, and applicability. Chem. Eng. J. 2016, 286, 640-662. [CrossRef]

11. Henderson, A.D.; Demond, A.H. Long-term performance of zero-valent iron permeable reactive barriers: A critical review. Environ. Eng. Sci. 2007, 24, 401-423. [CrossRef]

12. Wen, D.; Fu, R.; Li, Q. Removal of inorganic contaminants in soil by electrokinetic remediation technologies: A review. J. Hazard. Mater. 2021, 401, 123345. [CrossRef] [PubMed]

13. Xin, J.; Tang, F.; Yan, J.; La, C.; Zheng, X.; Liu, W. Investigating the efficiency of microscale zero valent iron-based in situ reactive zone (mZVI-IRZ) for TCE removal in fresh and saline groundwater. Sci. Total Environ. 2018, 626, 638-649. [CrossRef] [PubMed]

14. Gibert, O.; Assal, A.; Devlin, H.; Elliot, T.; Kalin, R.M. Performance of a field-scale biological permeable reactive barrier for in-situ remediation of nitrate-contaminated groundwater. Sci. Total Environ. 2019, 659, 211-220. [CrossRef]

15. Patil, S.S.; Shedbalkar, U.U.; Truskewycz, A.; Chopade, B.A.; Ball, A.S. Nanoparticles for environmental clean-up: A review of potential risks and emerging solutions. Environ. Technol. Innov. 2016, 5, 10-21. [CrossRef]

16. Luo, J.; Yu, D.; Hristovski, K.D.; Fu, K.; Shen, Y.; Westerhoff, P.; Crittenden, J.C. Critical review of advances in engineering nanomaterial adsorbents for metal removal and recovery from water: Mechanism identification and engineering design. Environ. Sci. Technol. 2021, 55, 4287-4304. [CrossRef]

17. Luo, J.; Fu, K.; Yu, D.; Hristovski, K.D.; Westerhoff, P.; Crittenden, J.C. Review of advances in engineering nanomaterial adsorbents for metal removal and recovery from water: Synthesis and microstructure impacts. ACS EST Eng. 2021, 1, 623-661. [CrossRef] 
18. Thanh, D.N.; Novák, P.; Vejpravova, J.; Vu, H.N.; Lederer, J.; Munshi, T. Removal of copper and nickel from water using nanocomposite of magnetic hydroxyapatite nanorods. J. Magn. Magn. Mater. 2018, 456, 451-460. [CrossRef]

19. Cai, C.; Zhao, M.; Yu, Z.; Rong, H.; Zhang, C. Utilization of nanomaterials for in-situ remediation of heavy metal(loid) contaminated sediments: A review. Sci. Total Environ. 2019, 662, 205-217. [CrossRef]

20. Ou, M.-Y.; Ting, Y.; Ch'ng, B.-L.; Chen, C.; Cheng, Y.-H.; Chang, T.-C.; Hsi, H.-C. Using mixed active capping to remediate multiple potential toxic metal contaminated sediment for reducing environmental risk. Water 2020, 12, 1886-1900. [CrossRef]

21. Sadat-Shojai, M.; Khorasani, M.T.; Dinpanah-Khoshdargi, E.; Jamshidi, A. Synthesis methods for nanosized hydroxyapatite with diverse structures. Acta Biomater. 2013, 9, 7591-7621. [CrossRef]

22. Fihri, A.; Len, C.; Varma, R.S.; Solhy, A. Hydroxyapatite: A review of syntheses, structure and applications in heterogeneous catalysis. Coordin. Chem. Rev. 2017, 347, 48-76. [CrossRef]

23. Liu, C.; Huang, Y.; Shen, W.; Cui, J. Kinetics of hydroxyapatite precipitation at pH 10 to 11. Biomaterials 2001, 22, 301-3016. [CrossRef]

24. Wang, P.; Li, C.; Gong, H.; Jiang, X.; Wang, H.; Li, K. Effects of synthesis conditions on the morphology of hydroxyapatite nanoparticles produced by wet chemical process. Powder Technol. 2010, 203, 315-321. [CrossRef]

25. Smičiklas, I.; Onjia, A.; Raičević, S.; Janaćković, Đ.; Mitrić, M. Factors influencing the removal of divalent cations by hydroxyapatite. J. Hazard. Mater. 2008, 152, 876-884. [CrossRef] [PubMed]

26. Marchegiani, F.; Cibej, E.; Vergni, P.; Tosi, G.; Fermani, S.; Falini, G. Hydroxyapatite synthesis from biogenic calcite single crystals into phosphate solutions at ambient conditions. J. Cryst. Growth 2009, 311, 4219-4225. [CrossRef]

27. Ni, M.; Ratner, B.D. Nacre surface transformation to hydroxyapatite in a phosphate buffer solution. Biomaterials 2003, 24, 4323-4331. [CrossRef]

28. Guo, Y.P.; Zhou, Y. Conversion of nacre powders to apatite in phosphate buffer solutions at low temperatures. Mater. Chem. Phys. 2007, 106, 88-94. [CrossRef]

29. Pham Minh, D.; Lyczko, N.; Sebei, H.; Nzihou, A.; Sharrock, P. Synthesis of calcium hydroxyapatite from calcium carbonate and different orthophosphate sources: A comparative study. Mater. Sci. Eng. B 2012, 177, 1080-1089. [CrossRef]

30. Naidu, S.; Scherer, G.W. Nucleation, growth and evolution of calcium phosphate films on calcite. J. Colloid Interf. Sci. 2014, 435, 128-137. [CrossRef]

31. Yang, F.; Liu, Y. Artificial hydroxyapatite film for the conservation of outdoor marble artworks. Mater. Lett. 2014, 124, 201-203. [CrossRef]

32. Graziani, G.; Sassonia, E.; Franzonia, E.; Scherer, G.W. Hydroxyapatite coatings for marble protection: Optimization of calcite covering and acid resistance. Appl. Surf. Sci. 2016, 368, 241-257. [CrossRef]

33. Ivanets, A.; Kitikova, N.; Shashkova, I.; Matrunchik, Y.; Kul'bitskaya, L.; Sillanpää, M. Non-acidic synthesis of phosphatized dolomite and its sorption behaviour towards $\mathrm{Pb}^{2+}, \mathrm{Zn}^{2+}, \mathrm{Cu}^{2+}, \mathrm{Cd}^{2+}, \mathrm{Ni}^{2+}, \mathrm{Sr}^{2+}$ and $\mathrm{Co}^{2+}$ ions in multicomponent aqueous solution. Environ. Technol. Innov. 2016, 6, 152-164. [CrossRef]

34. Fiol, N.; Villaescusa, I. Determination of sorbent point zero charge: Usefulness in sorption studies. Environ. Chem. Lett. 2009, 7, 79-84. [CrossRef]

35. Sheha, R.R. Sorption behavior of Zn(II) ions on synthesized hydroxyapatites. J. Colloid Interf. Sci. 2007, 310, 18-26. [CrossRef]

36. Meski, S.; Ziani, S.; Khireddine, H.; Boudboub, S.; Zaidi, S. Factorial design analysis for sorption of zinc on hydroxyapatite. J. Hazard. Mater. 2011, 186, 1007-1017. [CrossRef]

37. Klinkaewnarong, J.; Utara, S. Ultrasonic-assisted conversion of limestone into needle-like hydroxyapatite nanoparticles. Ultrason. Sonochem. 2018, 46, 18-25. [CrossRef]

38. Lei, S.; Shi, Y.; Qiu, Y.; Che, L.; Xue, C. Performance and mechanisms of emerging animal-derived biochars for immobilization of heavy metals. Sci. Total Environ. 2019, 646, 1281-1289. [CrossRef]

39. Ramasamy, V.; Anand, P.; Suresh, G. Synthesis and characterization of polymer-mediated CaCO3 nanoparticles using limestone: A novel approach. Adv. Powder Technol. 2018, 29, 818-834. [CrossRef]

40. Salimi, M.N.; Bridson, R.H.; Grover, L.M.; Leeke, G.A. Effect of processing conditions on the formation of hydroxyapatite nanoparticles. Powder Technol. 2012, 218, 109-118. [CrossRef]

41. Harding, I.S.; Rashid, N.; Hing, K.A. Surface charge and the effect of excess calcium ions on the hydroxyapatite surface. Biomaterials 2005, 26, 6818-6826. [CrossRef]

42. Corami, A.; Mignardi, S.; Ferrini, V. Copper and zinc decontamination from single- and binary-metal solutions using hydroxyapatite. J. Hazard. Mater. 2007, 146, 164-170. [CrossRef]

43. Šljivić, M.; Smičiklas, I.; Plećaš, I.; Mitrić, M. The influence of equilibration conditions and hydroxyapatite physico-chemical properties onto retention of $\mathrm{Cu}^{2+}$ ions. Chem. Eng. J. 2009, 148, 80-88. [CrossRef]

44. Wang, Y.J.; Chen, J.H.; Cui, Y.X.; Wang, S.Q.; Zhou, D.M. Effects of low-molecular-weight organic acids on Cu(II) adsorption onto hydroxyapatite nanoparticles. J. Hazard. Mater. 2009, 162, 1135-1140. [CrossRef]

45. Feng, Y.; Gong, J.L.; Zeng, G.M.; Niu, Q.Y.; Zhang, H.Y.; Niu, C.G.; Deng, J.H.; Yan, M. Adsorption of Cd (II) and Zn (II) from aqueous solutions using magnetic hydroxyapatite nanoparticles as adsorbents. Chem. Eng. J. 2010, 162, 487-494. [CrossRef]

46. Xu, Y.; Schwartz, F.W.; Traína, S.J. Sorption of $\mathrm{Zn}^{2+}$ and $\mathrm{Cd}^{2+}$ on hydroxyapatite surfaces. Environ. Sci. Technol. 1994, $28,1472-1480$. [CrossRef] 
47. Zhu, R.; Yu, R.; Yao, J.; Mao, D.; Xing, C.; Wang, D. Removal of $\mathrm{Cd}^{2+}$ from aqueous solutions by hydroxyapatite. Catal. Today 2008, 139, 94-99. [CrossRef]

48. Smičiklas, I.D.; Milonjić, S.K.; Pfendt, P.; Raičević, S. The point of zero charge and sorption of cadmium (II) and strontium (II) ions on synthetic hydroxyapatite. Sep. Purif. Technol. 2000, 18, 185-194. [CrossRef]

49. Fulmer, M.T.; Ison, I.C.; Hankermayer, C.R.; Constantz, B.R.; Ross, J. Measurements of the solubilities and dissolution rates of several hydroxyapatites. Biomaterials 2002, 23, 751-755. [CrossRef]

50. Stötzel, C.; Müller, F.A.; Reinert, F.; Niederdraenk, F.; Barralet, J.E.; Gbureck, U. Ion adsorption behaviour of hydroxyapatite with different crystallinities. Colloid Surface B 2009, 74, 91-95. [CrossRef]

51. Chemical Equilibrium Software Hydra and Medusa. Inorganic Chemistry Department, Royal Institute of Technology: Stockholm, Sweden. Available online: https://www.kth.se/che/medusa (accessed on 3 February 2021). 